
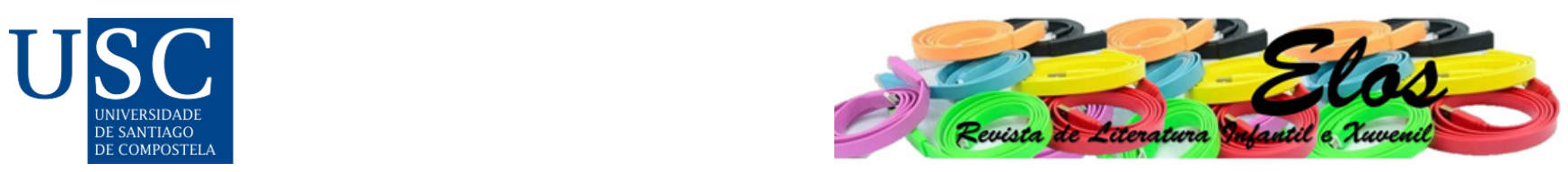

Elos: Revista de Literatura Infantil e Xuvenil, (8), 2021. ISSN-e: 2386-7620

https://doi.org/10.15304/elos.8.7969

Artigos

\title{
Deixem as crianças em paz: a censura de livros para crianças com temas LGBTIQ+
}

Dejen a la niñez en paz: la censura de libros para la infancia con temas LGBTIQ+ Leave the kids alone: the censorship of children's books with LGBTIQ+ themes

\author{
Emanuel Verdade da Madalena (iD \\ Universidade de Aveiro, Portugal \\ emanuelmadalena@gmail.com
}

Recibido: 27/09/2021; Aceptado: 07/11/2021

\section{Resumo}

No dia 19 de outubro de 2019, Paul Dorr transmitiu em direto no Facebook uma ação de protesto onde queimou quatro livros para crianças com temas LGBTIQ+, que havia requisitado na biblioteca pública de Orange City, no estado de Iowa. Alguns desses livros estão frequentemente presentes nas listas anuais dos dez livros mais censurados nas bibliotecas públicas dos EUA, que incluem quase exclusivamente livros para a infância e juventude, e a maioria contém temas e/ou personagens LGBTIQ+. Assim, este artigo parte de uma análise aos temas e características dos livros mais censurados nos EUA, através das listas compiladas desde 2001 pela American Library Association, para contextualizar a questão da censura aos livros para crianças com temas LGBTIQ+, salientando a forma como se tornaram predominantes nessas listas ao longo dos últimos anos. Partindo da questão clássica do duplo destinatário que influencia de forma indelével o subsistema literário da literatura para a infância (Shavit, 2004), discutem-se as características que, por um lado, mostram a importância da presença destes temas na literatura para a infância (Bartholomaeus e Riggs, 2019; Madalena e Ramos, 2021), mas que, por outro lado, a tornam um campo de batalha ideológico (Stephens, 2018).

Palavras chave: literatura infantil; censura; LGBTIQ+; diversidade de género; orientação sexual.

\section{Resumen}

El día 19 de octubre de 2019, Paul Dorr retransmitió en directo en Facebook una acción de protesta donde quemó cuatro libros para la infancia con temas LGTBIQ+, que había conseguido en la biblioteca pública de Orange City, en el estado de Iowa. Algunos de eses libros están presentes con frecuencia en las listas anuales de los diez libros más censurados en las bibliotecas públicas de los EUA, a través de las listas realizadas desde 2001 por la American Library Association, para contextualizar la cuestión de la censura de libros para la infancia con temas LGTBIQ+, destacando la manera en que se volvieron predominantes en estas listas a lo largo de los últimos años. Partiendo de la cuestión clásica del doble destinatario que influye de manera inevitable sobre el subsistema literario de la literatura infantil (Shavit, 2004), se discuten las características que, por una parte, muestran la importancia de la presencia de estos temas en la literatura 
infantil (Bartholomaeus y Riggs, 2019; Madalena y Ramos, 2021), pero que también la convierten en un campo de batalla ideológico (Stephens, 2018).

Palabras clave: literatura infantil; censura; LGTBIQ+; diversidad de género, orientación sexual.

\begin{abstract}
On October 19, 2019, Paul Dorr broadcast live on Facebook a protest action in which he burned four books for children with LGBTIQ+ themes, which he had ordered from the public library in Orange City, Iowa. Some of these books are frequently featured in the annual lists of the ten most censored books in US public libraries, which include almost exclusively books for children and youth, and most contain LGBTIQ+ themes and/or characters. Thus, this article starts from an analysis of the themes and characteristics of the most censored books in the US, through lists compiled since 2001 by the American Library Association, to contextualize the issue of censorship of books for children with LGBTIQ+ themes, highlighting how they became predominant on these lists over the past few years. Starting from the classic question of the dual addressee that indelibly influences the literary subsystem of literature for children (Shavit, 2004), the characteristics that, on the one hand, show the importance of the presence of these themes in literature for children are discussed (Bartholomaeus and Riggs, 2019; Madalena and Ramos, 2021), but which, on the other hand, make it an ideological battleground (Stephens, 2018).
\end{abstract}

Keywords: children's literature; censorship; LGBTIQ+; gender diversity; sexual orientation.

\title{
INTRODUÇÃO
}

No dia 19 de outubro de 2018, Paul Dorr transmitiu em direto no Facebook uma ação de protesto em que queimou quatro livros para crianças e adolescentes com temas LGBTIQ+ (Figura 1), que havia requisitado na biblioteca pública de Orange City, no estado de Iowa. No vídeo de 30 minutos, o ativista cristão (como Dorr se identificava) refere explicitamente que se inspirou numa queima de livros levada a cabo por nazis em maio de 1933, num instituto de sexologia em Berlim conhecido pela sua notável biblioteca sobre homossexualidade e transexualidade. Em resposta, nos dias seguintes, mais de 200 livros foram doados à biblioteca pela população. 
Figura 1. Capas dos quatro livros queimados por Paul Dorr
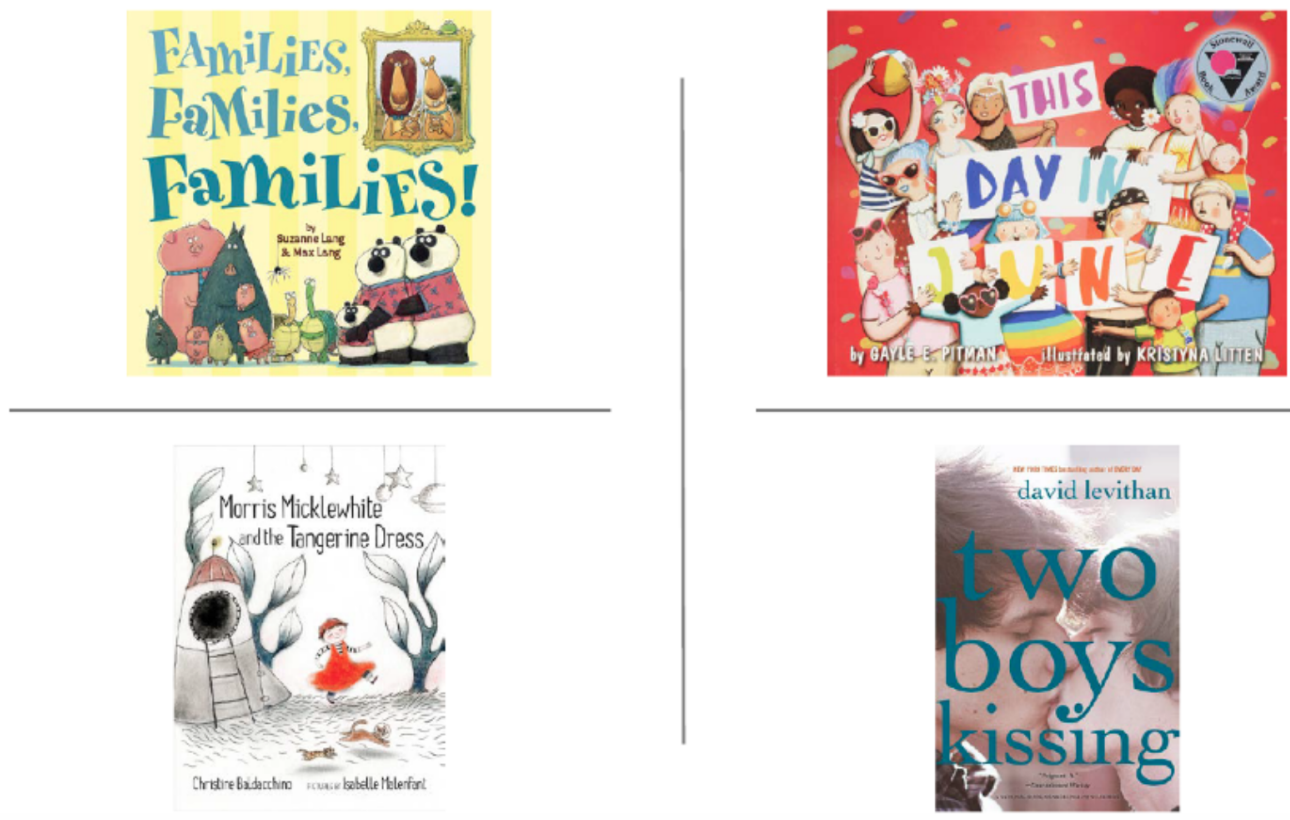

O homem, que não se mostrou arrependido no julgamento, foi condenado a pagar uma multa por ter roubado e destruído propriedade pública, sem qualquer sanção ou menção ao discurso e atos de ódio contra minorias.

É provável que, quando pensamos em censura de livros, invoquemos este tipo de imagens de pequenas ou grandes queimas de livros, mas ela ocorre, muitas vezes, de forma mais insidiosa e invisível, e, no caso da literatura para a infância, parte de um pressuposto universal e, aparentemente, pacífico: é necessário separar o que é apropriado para as crianças daquilo que não é. Assim, é natural que qualquer pessoa estabeleça um limiar a partir do qual concorda que um determinado livro não possa ser acedido por crianças. Se outra pessoa não concordar com esse limite, pode acusar a primeira de censura. Trata-se, claro, de uma diferença nos padrões morais e éticos entre essas duas pessoas, que pode justificar a objeção à mensagem (real ou imaginada) de um livro ou, até, à presença de uma só palavra, repetida ou não, que se considera imprópria.

No entanto, arrepiamo-nos com as imagens das fogueiras dos nazis e tendemos, como sociedade, para a defesa da liberdade de expressão, ancorada no reconhecimento e respeito pela diversidade moral, ética e humana - mas o nosso compromisso com essa liberdade parece tornarse imediatamente mais difuso quando se trata de crianças, e continuamos sem questionar o quão ténue pode ser a diferença entre seleção e censura, e a aceitar uma espécie de mínimo denominador comum que deixa de fora muitas ideias, muitas mundividências, e, no fundo, muitas crianças.

Como veremos, três dos livros que foram queimados nesse protesto no Facebook estão presentes nas listas anuais dos dez livros mais censurados nas bibliotecas públicas dos Estados Unidos da América, divulgadas durante a Banned Books Week - ou "semana dos livros banidos" - promovida pela American Library Association (Figura 2), normalmente na última semana de setembro, em defesa da liberdade de expressão. Essas listas incluem quase exclusivamente livros para a infância e juventude e a maioria contém temas e/ou personagens LGBTIQ+. 
Figura 2. Imagem promocional da Banned Books Week

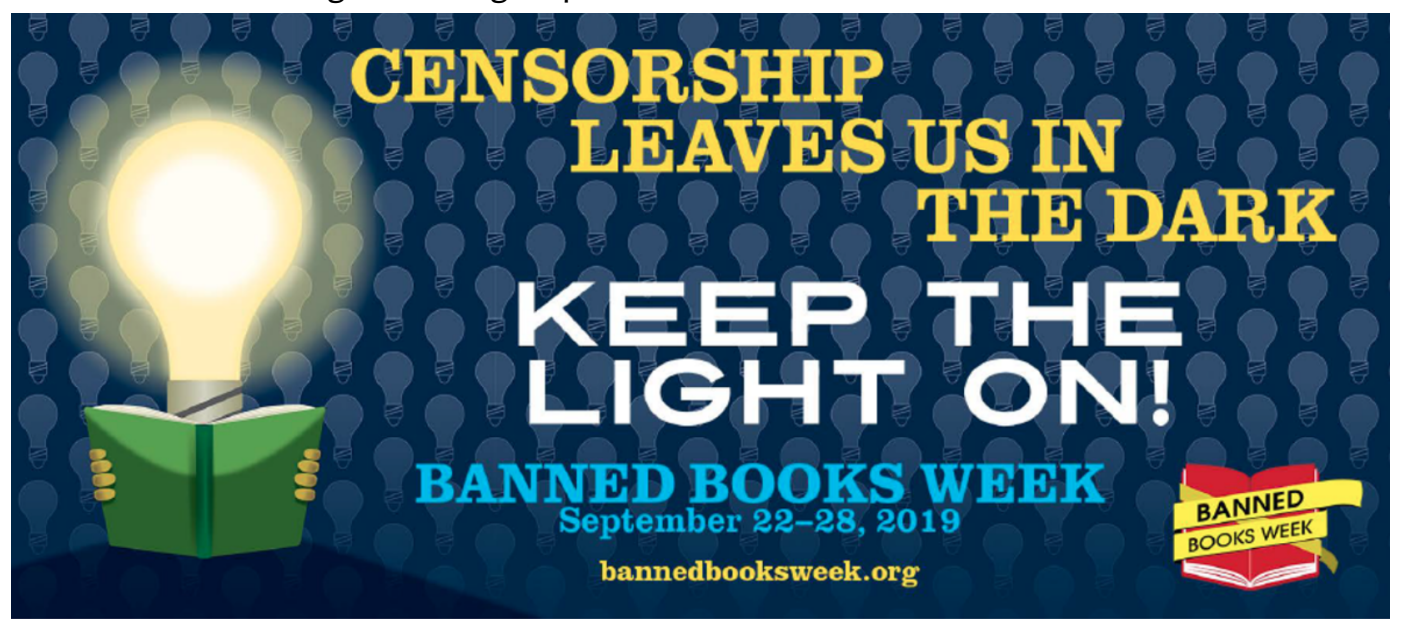

Também no Brasil, por exemplo, vêm surgindo, já desde o governo de Michel Temer, cada vez mais casos de livros retirados das escolas, por vezes também com conteúdos LGBTIQ+. Um dos casos mais recentes de censura no Brasil aconteceu no início de setembro de 2019 e foi um dos que mais repercussão teve nos média, quando fiscais da prefeitura do Rio de Janeiro se deslocaram à Bienal do Livro para recolher uma edição de banda desenhada chamada Vingadores - A Cruzada das Crianças, que inclui um beijo entre dois homens (Figura 3) - um livro de 2012 que já estava publicado no Brasil desde 2016. Isto aconteceu depois de o prefeito do Rio de Janeiro, Marcelo Crivella, ordenar a recolha da banda desenhada, alegando ser preciso proteger as crianças de conteúdos que considera impróprios - neste caso, um beijo entre dois homens - e que não é correto que as crianças tenham acesso precoce a assuntos que não estão de acordo com as suas idades, como escreveu no Twitter. Marcelo Crivella, evangélico, bispo fora de funções da Igreja Universal do Reino de Deus, posiciona-se publicamente contra a chamada "ideologia de género", ao lado de, como sabemos, Jair Bolsonaro, o atual presidente do Brasil.

Seja pelo poder político, como no Brasil, ou a partir da pressão social, como nos Estados Unidos, a reação ao movimento de visibilização e em prol dos direitos LGBTIQ+ ocorre um pouco por todo o ocidente, muitas vezes na proporção direta dos progressos alcançados nos últimos anos. 
Figura 3. Página de Vingadores - A Cruzada das Crianças que motivou a censura

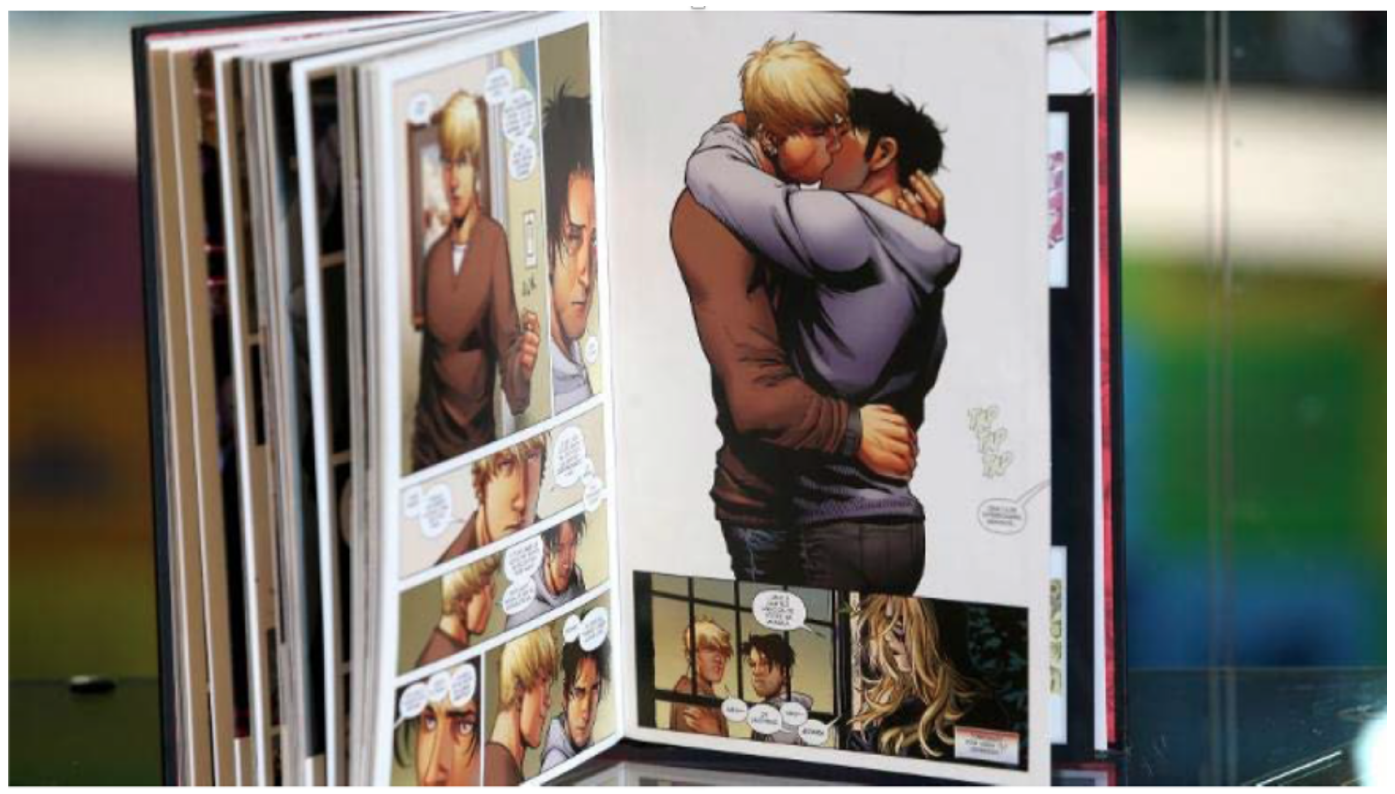

Este texto parte, assim, de uma breve análise aos temas e características dos livros mais censurados nos Estados Unidos, através das listas compiladas desde 2001 pela American Library Association, para contextualizar a questão da censura aos livros para crianças com temas LGBTIQ + , salientando a forma como se tornaram predominantes nessas listas ao longo dos últimos anos.

\section{AS ROLDANAS DA CENSURA}

Além das dimensões estética e lúdica da literatura para a infância, a sua dimensão ética é especialmente importante por contribuir para a socialização e formação da personalidade das crianças, transmitindo, reforçando e/ou ampliando valores e conceções sobre o mundo que as rodeia, incluindo o que vai além do seu contexto sociocultural e familiar (ver Hamilton, Anderson, Broaddus e Young, 2006; Johnston, 2011; Madalena e Ramos, 2021). A literatura para crianças pode ser, assim, uma espécie de legado cultural das mais velhas para as mais novas gerações de uma sociedade, mas não tem de partir apenas dos seus conceitos e valores mais tradicionais. Esse legado pode provir das gerações imediatamente mais próximas, ou de quaisquer pessoas que pretendem fazer evoluir esses mesmos conceitos e valores. De forma mais ou menos consciente, e a partir da introdução de novos temas e representações, a literatura para a infância apresenta essa evolução às novas gerações. Como refere Zohar Shavit: "desde o seu início, os livros para crianças foram escritos com uma certa ideia da criança em mente; quando esta ideia mudou, os textos para crianças também mudaram" (Shavit, 2004, pp. 26-27).

Desta forma, a dimensão ética e formativa da literatura infantil não desaparece; apenas altera o seu conteúdo, uma vez que, assim como a produção mais clássica pretende fazer com os conceitos mais tradicionais, também uma literatura para a infância com novos conceitos e representações sociais pretende transmiti-los e cimentá-los nas crianças. É deste movimento que emergem, muitas vezes, temas fraturantes, ou controversos na literatura para a infância (ver Evans, 2015; Ramos, Mourão e Cortez, 2017; Reynolds, 2007). Esses temas emergentes são, tendencialmente, 
temporários e fugidios, uma vez que podem ser assimilados pela literatura infantil de forma relativamente rápida, a partir do momento em que chegam ao mainstream (o tema do divórcio parece ser um bom exemplo). Estes temas incluem, por exemplo, questões multiculturais, políticas, ambientalistas e de direitos humanos, normalmente (ou previamente) não conotadas com a infância, tal como a diversidade nas identidades de género e orientações sexuais, ou seja, as questões LGBTIQ+.

Neste caso, a presença destes temas na literatura infantil pode fornecer importantes referentes identitários a crianças que não se veem representadas nas produções culturais. A si mesmas, no caso das suas identidades de género, por exemplo, ou aos seus familiares e famílias não tradicionais ou não heteronormativos, por exemplo. Além disso, fazem parte de um esforço de prevenção primária contra a homofobia e a transfobia (Platero, 2014, p. 219) e, claro, podem ser importantes fontes de informação e empatia para a sociedade em geral. Se a questão da importância da luta contra a homofobia, desde a infância, já está mais disseminada como valor básico das sociedades, a questão da diversidade de género ainda tem mais caminho por percorrer. No entanto, é precisamente esta que tem mais urgência logo desde a primeira infância, uma vez que a diversidade de género manifesta-se (ou pode manifestar-se) logo na primeira infância (ver Brill e Pepper, 2008; Cano Oncala, Esteva Antonio e Bergero, 2006; Gavilán, 2018; GillPeterson, 2018; Platero, 2014) precisamente porque "no momento em que as crianças começam a ter um conhecimento dos esquemas de género e rotular de uma forma precisa elas próprias como sendo menina ou menino, elas tentam adaptar-se a estes esquemas e usá-los para avaliar o comportamento dos outros" (Rodrigues, 2003, p. 23). Dito de outra forma, a diversidade de género é uma parte integrante da infância, mesmo que não esteja presente no quotidiano de todas as crianças. Além de estar cada vez mais presente no discurso social, político, académico e científico, a diversidade de género faz parte de nós e das nossas realidades, faz parte do lúdico entre as crianças, das representações e dinâmicas que cercam o universo sociocultural.

Por outro lado, principalmente em seus aspetos tradicionais e binários, o género é uma presença constante na literatura infantil (ver Brugeilles, Cromer e Cromer, 2002; McCabe, Fairchild, Grauerholz, Pescosolido e Tope, 2011; Weitzman, Eifler, Hokada e Ross, 1972). A relevância da presença da diversidade de género na literatura infantil é a mesma das ideias tradicionais de género: a representação de valores e conceitos que existem na sociedade, indo de uma simples descrição que espelha a realidade a uma pedagogia normativa intencional. Em última análise, isso é suficiente para justificar a importância da presença da diversidade de género na literatura infantil, uma vez que não haveria nenhuma razão aparente para que a normalização e visibilidade dessas identidades não fossem acompanhadas pela sua representação na cultura. Além de poderem proporcionar valiosos referentes identitários, esses livros podem ser usados em sessões escolares simplesmente para discutir aspetos de género, especialmente porque eles oferecem uma perspetiva mais ampla, e muitas vezes mais matizada, do assunto, em vez de uma leitura prescritiva e restrita.

O facto de os livros para crianças serem vistos como "espelhos culturais que refletem as posições sociais mais amplamente consideradas como aceitáveis" (Johnston, 2011, p. 154) é especialmente ratificado pela importância dada pela sociedade à qualidade dos livros ao dispor das crianças. Assim como os livros podem ser aconselhados ou disponibilizados de formas mais ou menos oficiais pelo poder público, garantindo assim a sua adequação aos valores dominantes, também o oposto é possível, quando existe alguma forma de censura formal - e, claro, informal - a certos livros. Isto acontece devido a uma característica particular do subsistema literário da literatura para a infância: a questão do duplo destinatário, como Zohar Shavit apresentou já em 1983, na sua obra Poética da 
Literatura para Crianças (2004). Ou seja, o facto de os livros terem de agradar também aos adultos. Shavit diz que

a sociedade espera que o escritor para crianças seja apreciado tanto pelos adultos (e especialmente pelas "pessoas da cultura") como pelas crianças. No entanto, esta exigência não só é complexa como é até contraditória por natureza, devido aos gostos diferentes e até incompatíveis das crianças e dos adultos. [...] 0 critério para uma avaliação positiva de um livro para crianças, se não é educativo, é o seu sucesso em agradar ao público adulto. (Shavit, 2004, pp. 64-65)

Esta problemática da presença de temas controversos na literatura para a infância e sua consequente censura é determinada por um fator essencial: os próprios gostos dos adultos são contraditórios, incompatíveis, diferentes entre si. Assim, a existência deste duplo destinatário ajuda, por um lado, a que a diversidade de género e orientações sexuais surja na literatura para a infância (porque os adultos querem transmitir determinados conceitos progressistas às crianças), mas, por outro lado, também explica a censura a que pode estar sujeita.

0 grande peso dado à dimensão ética da literatura para a infância é também essencial, já que, muitas vezes, uma obra é aprovada pelos adultos apenas, ou quase, por transmitir algum valor, algum conhecimento considerado correto ou desejável para esses mesmos adultos - é isso que faz com que um mesmo livro para a infância seja adotado entusiasticamente por uns e censurado por outros, no caso dos temas controversos. Assim, a censura existe porque os livros são apelativos para os adultos, sim, mas para os adultos errados - os que têm valores que certos poderes antidemocráticos consideram indesejáveis e dignos de repressão, quando não punição.

\section{CONTABILIZANDO A CENSURA}

A diversidade de género e as sexualidades ou parentalidades não heteronormativas são, então, especialmente censuradas nos livros para crianças, muitas vezes formalmente, em países como os Estados Unidos da América, especialmente em estados mais conservadores. Na lista anual dos dez livros mais desafiados encontram-se normalmente vários livros com temáticas LGBTIQ + (juntamente com livros censurados por conteúdos percecionados como sendo sexualmente explícitos, racistas, violentos, promotores de educação sexual, por representarem o suicídio, abuso de álcool e drogas, ou por conterem palavrões, nudez ou uma perspetiva religiosa), e sempre para um público jovem ou infantil.

Antes de 2001, a associação não compilava a informação da mesma forma. Ainda assim, comparando o número total de livros censurados entre a década de 1990 a 1999 e a de 2000 a 2009 (Figura 4), verificamos que o número total de livros visados por terem temáticas LGBTIQ + , nomeadamente pela presença de homossexualidade, se manteve semelhante, baixando até um pouco na década mais recente. No entanto, a pesquisa que conseguimos fazer com os poucos dados disponíveis parece indicar que o número desses livros no top 10 nunca seria significativo, e, com mais relevância para esta análise, praticamente nenhuns desses livros seriam para crianças, mas predomi-nantemente para jovens. 0 facto de a publicação de livros para crianças com temas LGBTIQ + ser, especialmente na década de 1990, ainda marginal (nos dois sentidos da palavra), ajuda a explicar este facto. 
Figura 4. Número de livros censurados entre 1990-99 e 2000-09, distribuídos por motivo

\section{Challenges by Reasons}

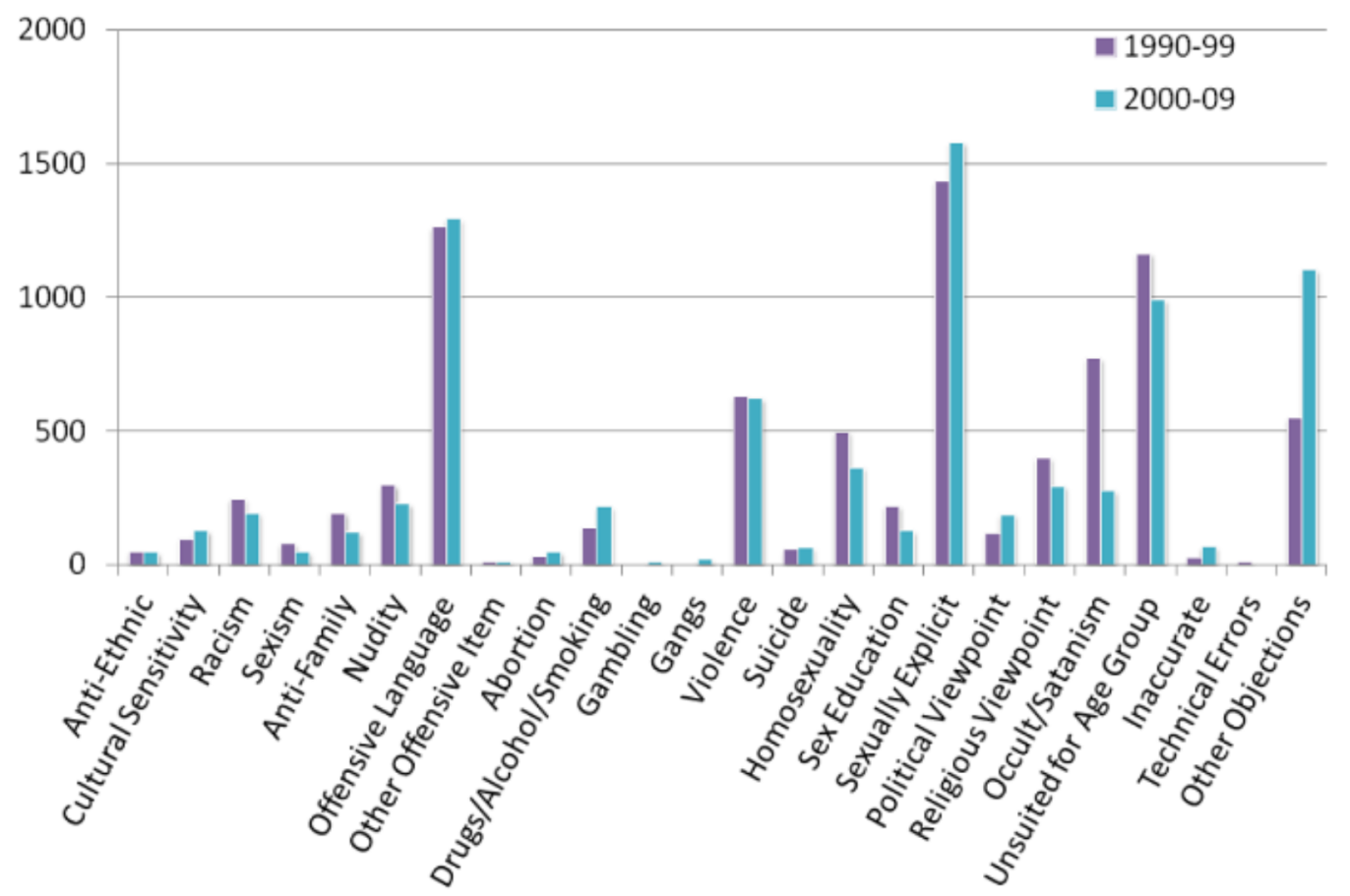

Em relação ao top dos 10 livros mais censurados em cada ano (Figura 5), podemos verificar como, a partir do ano 2001, ainda sem qualquer livro, a presença de livros com temas LGBTIQ+ seguiu duas tendências essenciais. A primeira é a presença constante de mais do que um livro no top 10, exceto em 2011 e 2013, anos que representam uma aparente regressão na tendência constante de pelo menos 3 livros entre 2006 e 2009. Fica por explicar a razão dessa diminuição, antes do aumento considerável nos últimos anos, chegando-se a uns impressionantes 7 livros censurados por razões que incluem, entre outras, a presença de temas LGBTIQ+. A lista de 2018 teve, excecionalmente, 11 livros, mas ainda assim é o ano com uma maior percentagem de livros com estes temas, depois de dois anos, 2016 e 2017, em que metade dos livros do top os continham. Com efeito, a presença de conteúdos LGBTIQ+é, agora, a razão mais frequente, com o motivo específico da não-conformidade de género também a destacar-se. 
Figura 5. Número de livros censurados por conterem temas LGBTIQ+, por ano

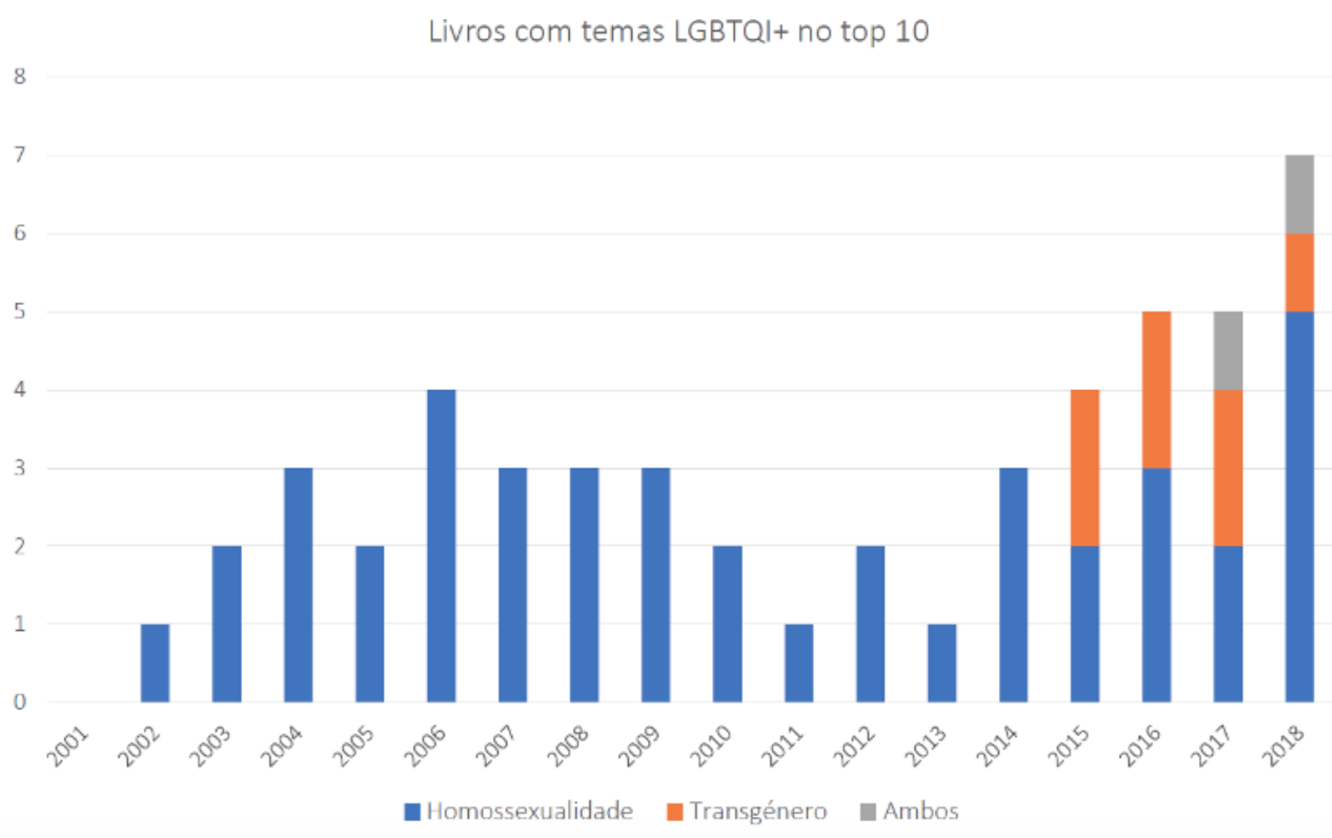

"Censurado", neste caso, quer dizer "visado", alvo de pedidos de retirada de bibliotecas públicas e/ou escolares, e não necessariamente de livros efetivamente banidos. Quem inicia estes pedidos são, principalmente, pais e mães, especialmente no caso das bibliotecas escolares, e os utilizadores em geral, no caso das bibliotecas públicas (Figura 6). Segundo a associação, os casos destes livros controversos que são vandalizados, escondidos e roubados das bibliotecas estão a aumentar nos últimos anos.

Figura 6. Distribuição das pessoas/entidades que iniciam os pedidos de retirada dos livros

\section{WHO INITIATES CHALLENGES}

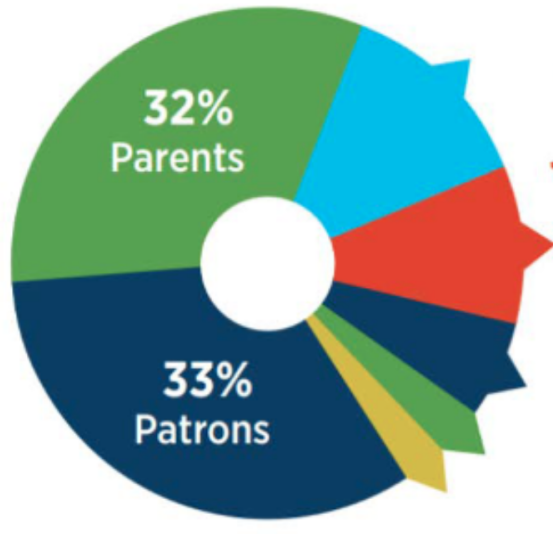

\section{$13 \%$ Board/administration}

$10 \%$ Librarians/teachers

$6 \%$ Political/religious groups

$3 \%$ Elected officials

\section{$3 \%$ Students}

Statistics based on 335 responses

Quanto aos livros para a infância, nenhum é tão visado como o And Tango Makes Three - em português, Três com Tango -, que conta a história real passada num jardim zoológico em Nova 
Iorque de um casal de pinguins macho, ao qual o tratador deu a oportunidade de ter uma cria, colocando um ovo no seu ninho. Este livro ilustrado, publicado em 2005, entrou diretamente para primeiro lugar do top de 2006, onde se manteve até 2010, exceto em 2009, quando foi o segundo livro mais censurado. Continua a aparecer frequentemente na lista, pelo menos até 2017.

É interessante reparar que muitos destes livros estão traduzidos em português e deram inclusive origem a adaptações audiovisuais, ou seja, são livros que conseguiram ter uma visibilidade e disseminação considerável. Seria importante tentar perceber o efeito que a censura e consequente exposição dessa mesma censura tem na visibilidade destes livros - é esse, aliás, um dos principais objetivos da campanha anual sobre os livros mais censurados levada a cabo pela American Library Association. No entanto, parece claro que a censura, por sua vez, surge precisamente do facto de alguns livros alcançarem um certo limiar de visibilidade - já para não falar de livros clássicos não LGBTIQ+ que começaram recentemente a ser desafiados, como o clássico norte-americano Mataram a Cotovia, de Harper Lee, que apareceu no top 10 de 2009, 2011 e 2017 devido a uma campanha de revisionismo que procurou censurar este clássico norte-americano amplamente estudado nas escolas devido à presença de violência e, especialmente, por usar abundantemente insultos raciais - proferidos, claro, por personagens racistas, num livro que é celebrado por enfrentar esse mesmo racismo. Da mesma forma, outros clássicos norte-americanos bastante lidos e estudados nas escolas aparecem nestes tops, como vários romances de Toni Morrison ou clássicos como À Espera no Centeio, de J. D. Salinger, e Ratos e Homens, de John Steinbeck, ao qual se aponta também a presença de linguagem ofensiva, violência e racismo.

A partir de 2015, o top passou a incluir, sistematicamente, livros com o tema da diversidade de género em geral, e, particularmente, livros com personagens transgénero, como o livro I Am Jazz (Figura 7), publicado em 2014, sobre a história real de uma menina transgénero - Jazz Jennings, uma das autoras - e a sua transição pública aos cinco anos de idade.

Figura 7. Capas de I Am Jazz (2014) e George (2015)
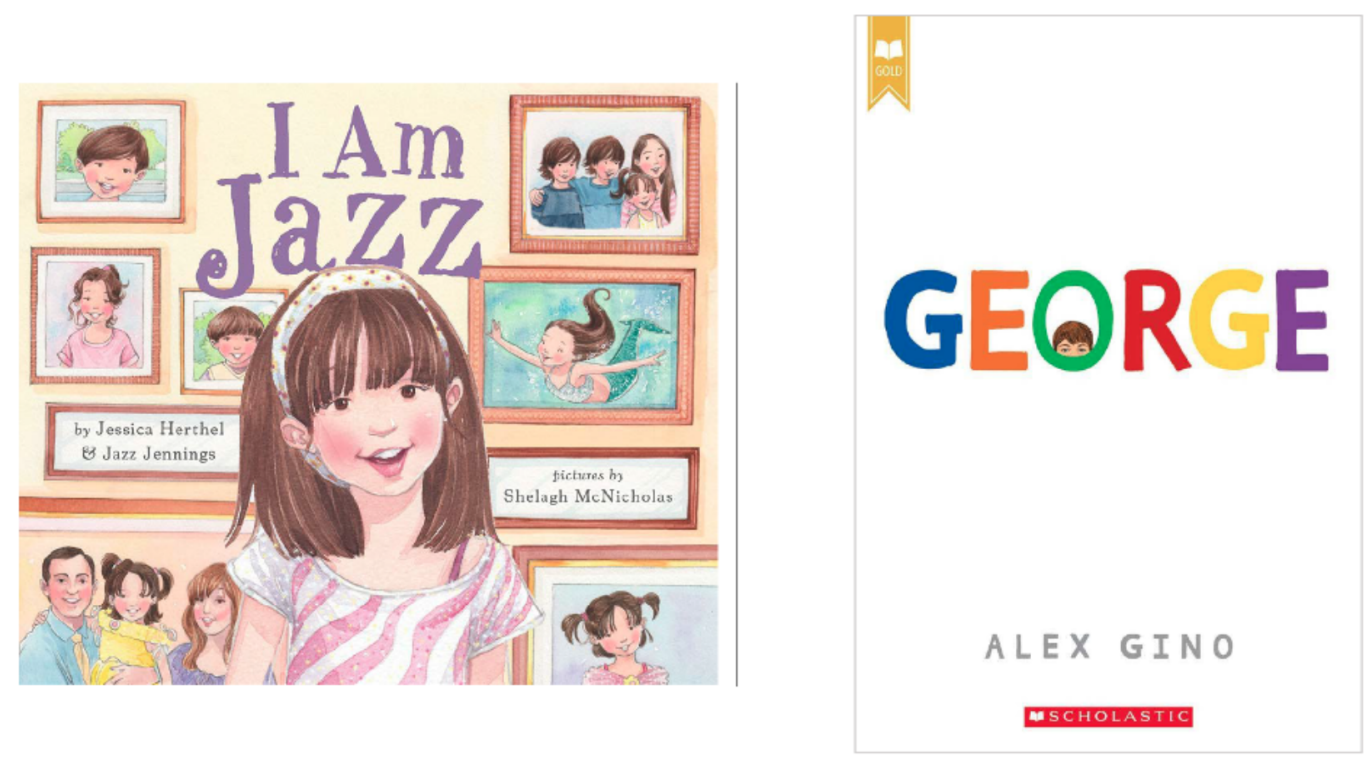

A principal razão apresentada para censurar este livro é, precisamente, o facto de ter uma protagonista transgénero, tal como acontece com o romance George (Figura 7), publicado em 2015, dirigido a leitores dos oito aos doze anos, cujo protagonista é também uma criança 
transgénero. Além disso, também são referidas razões como linguagem inapropriada, pontos de vista ofensivos, imprecisões, inadequação etária, conteúdos de educação sexual e, até, erradamente, homossexualidade.

Encontra-se também nestas listas o livro Beyond Magenta: Transgender Teens Speak Out (Figura 8), publicado em 2014 - um livro de não-ficção sobre adolescentes transgénero, não-binários e de género neutro, com entrevistas e fotografias que mostram o seu percurso individual -, censurado por ser percecionado como sendo anti-família e inadequado para a faixa etária a que se dirige, por ter linguagem considerada ofensiva, pontos de vista políticos e religiosos, conteúdos homossexuais e, mais uma vez, pelo pecado capital de promover a educação sexual. A propósito, o livro Sex is a Funny Word (Figura 8), publicado em 2015, é explicitamente de educação sexual (para crianças dos 7 aos 10 anos) e, como é impressionantemente vanguardista e inclui uma grande diversidade de corpos, orientações sexuais e identidades de género, teve lugar na lista de 2017.

Figura 8. Capas dos livros Beyond Magenta: Transgender Teens Speak Out (2014) e Sex is a Funny Word (2015)
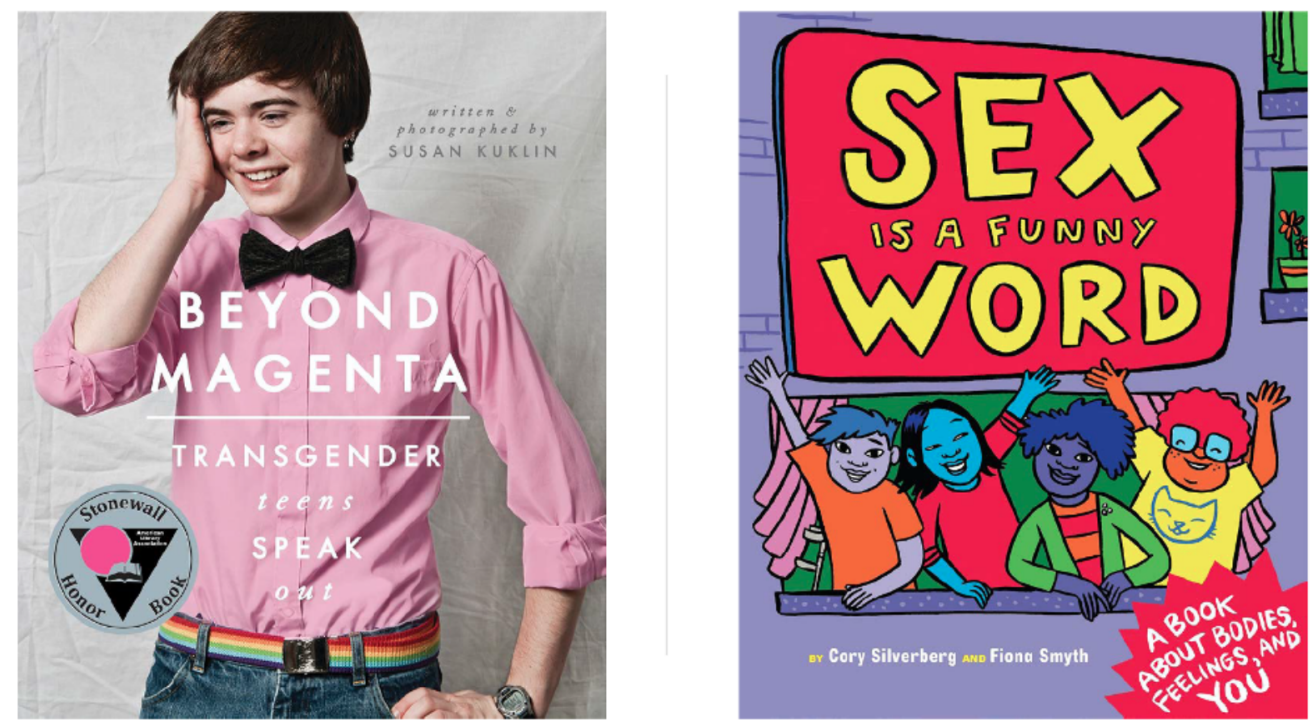

Também o livro-álbum This Day in June (Figura 9), de 2014, inclui tanto o tema da homossexualidade como da diversidade de género, no seu texto em rima sobre uma parada de orgulho LGBTIQ+, com referências à história do movimento. Este livro aparece na lista de 2018, ano em que foi queimado no protesto em Orange City que referi no início, juntamente com o já mencionado Two Boys Kissing e Families, Families, Families (Figura 9), publicado em 2015, um livro ilustrado para crianças dos 3 aos 7 anos sobre os mais diversos tipos de família. Aparentemente, a representação de famílias não-tradicionais é muito ameaçadora, mesmo que sejam famílias de animais. 
Figura 9. Capas dos livros This Day In June (2014) e Families, Families, Families (2015)
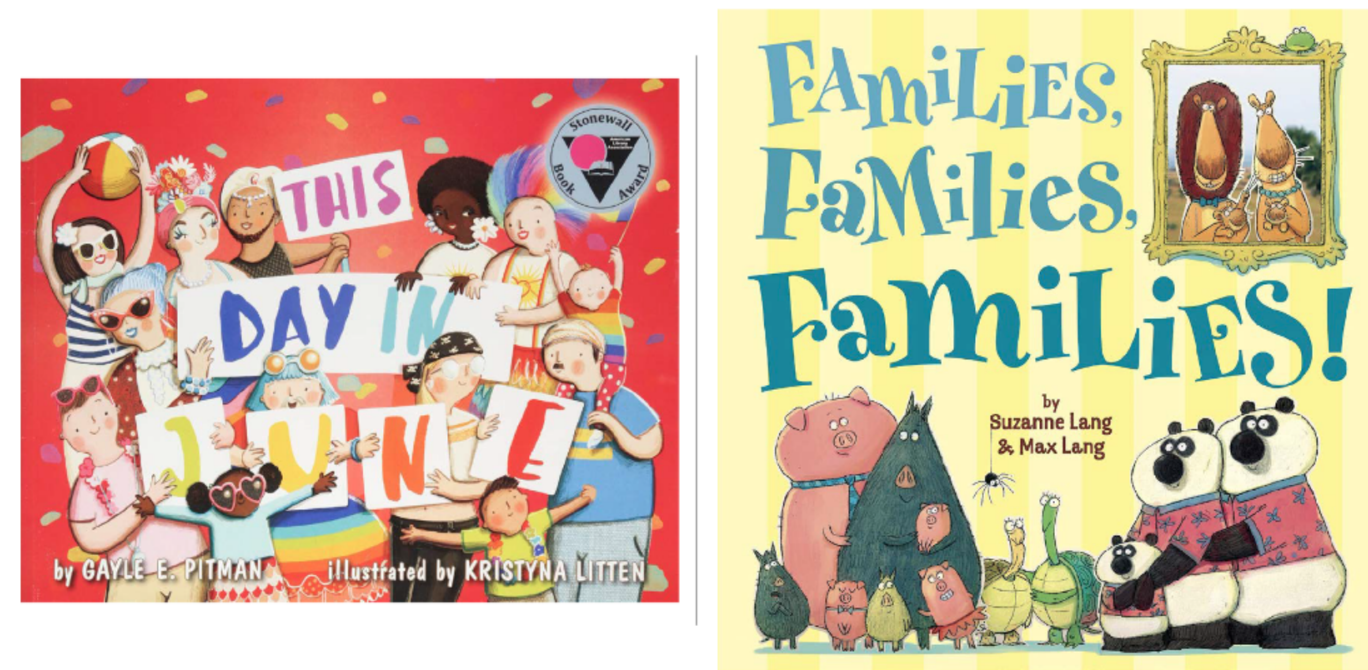

\section{COMO DEIXAR AS CRIANÇAS EM PAZ?}

É difícil fugir à questão clássica do duplo destinatário que influencia de forma indelével o subsistema literário da literatura para a infância (Shavit, 2004): por um lado, alguns adultos consideram importante a presença de certos temas na literatura para a infância (Bartholomaeus e Riggs, 2019), mas, por outro lado, alguns adultos rejeitam-na veementemente. Entretanto, a literatura para a infância torna-se um campo de batalha ideológico para os adultos (Stephens, 2018).

Como sabemos, o duplo destinatário existe através da influência dos mediadores de leitura, sejam eles pais, educadores, ou outros. No entanto, em relação a estes livros, ou temas, constantemente desafiados não são apenas os mediadores que sentem necessidade de dirigir a escolha das leituras das crianças, mas também a sociedade em geral, mostrando que a literatura infantil até pode ter um triplo destinatário, uma vez que as motivações dos segundos e dos terceiros são algo diferentes entre si.

Além disso, nestes livros, em geral, o papel dos pais, educadores e outros mediadores é percecionado como ainda mais preponderante, especialmente por se apresentar com um conteúdo político mais explícito (apesar de todas as decisões, ou aparente ausência destas, constituírem sempre um ato político, ainda que numa pequena escala). Escolher conscientemente um livro não sexista e não cisnormativo que represente alguma forma de diversidade de género; ou, por outro lado, escolher, ou aceitar acriticamente, um livro tradicionalista pode ser um ato simbólico de uma atitude política em relação a essas questões.

Este papel dos mediadores começa no momento da escolha de um livro que celebre a aceitação da diferença e a visibilidade da diversidade de género, rejeitando aqueles que promovem o sexismo e a valorização dos papéis tradicionais de género, mas também abrange a influência retroativa que essa escolha pode ter, especialmente sobre os editores, que, é claro, reagem à demanda do mercado. Isto não significa que livros explicitamente sexistas ou cisnormativos devam ser censurados, nomeadamente os clássicos. Pelo contrário, os mediadores podem usar essas narrativas para analisar, questionar e discutir esses conceitos com as crianças e, assim, promover a igualdade e o 
respeito da diversidade na identidade e expressão de género (Chatton, 2001; Lehr, 2001). Já em 1999, Jody Norton apontava que a partir da reconceptualização de género é possível transpor o conteúdo de livros existentes para as questões da diversidade de género (Norton, 1999, p. 416).

Além disso, existem estudos - como Narahara (1998) e Scott (1986), que mostram que não só o contacto com livros e histórias não sexistas, diligentes em prol da igualdade de género, promove uma redução de conceções estereotipadas em crianças e jovens, mas também que o debate sobre género nas histórias, mesmo nas sexistas, contribui para esse efeito, conforme discutido em Paynter, 2011, e Nunes, 2017.

Como Susan Lehr sugere para um contexto escolar, embora o mesmo se aplique a qualquer contexto de alfabetização ou mediação com crianças:

A central feature of a balanced literature program includes time for children to have honest and extensive conversations about the themes, settings, and characters found in literature. The questions, concerns, conflicts, and prejudices of the children are all valid topics of conversations. Making children echo politically correct thinking is not the goal [...]. The opinions and attitudes of the children will be as diverse as the number of children in the classroom. Through these dialogues children will be able to think about some of the most basic tenets of what it means to be human. (Lehr, 2001, p. 17)

Voltando à questão da censura, as ameaças percecionadas (e feitas) pelo lado da batalha que reage (talvez desproporcionalmente) à homossexualidade e à diversidade de género são justificadas, frequentemente, pela necessidade de proteger as crianças daquilo a que os movimentos conservadores chamam (incorretamente) de ideologia de género, pelo que é natural que os livros para a infância progressistas e inclusivos se tornem um alvo a abater.

Mas, para que não haja dúvidas, a ideologia de género é a que vem existindo há muitas gerações,

é a construção sociocultural tradicional e essencialista do género, uma verdadeira ideologia normativa imposta aos indivíduos. E deixar as crianças em paz não é invalidar as suas identidades e não atender às suas necessidades, promovendo a desinformação, a perseguição, o bullying e a intolerância.

Deixar as crianças em paz não é censurar-lhes os livros, é deixá-las ler aquilo que lhes interessa e que de alguma forma é importante para elas (mesmo que sejam só livros divertidos, sem uma dimensão ética considerável). Deixar as crianças em paz não é censurar os livros que possam transmitir valores cada vez mais importantes - livros com todas as cores do arco-íris, para que todas as crianças se possam reconhecer em personagens como elas ou como os seus familiares e amigos. Para que todas as crianças possam encontrar o desvelo, a empatia, as respostas que uma parte da sociedade, infelizmente, não lhes quer dar. Dessa forma, sim, deve deixar-se as crianças em paz.

\section{Referências bibliográficas}

Bartholomaeus, C., e Riggs, D. W. (2019). 'Girl brain ... boy body': representations of trans characters in children's picture books. Em R. Pearce, I. Moon, K. Gupta, e D. L. Steinberg (Eds.), The Emergence of Trans: Cultures, Politics and Everyday Lives (pp. 135-148). Routledge.

Brill, S., e Pepper, R. (2008). The transgender child. Cleis Press Inc.

Brugeilles, C., Cromer, I., e Cromer, S. (2002). Male and Female Characters in Illustrated Children's Books or How children's. A literature contributes to the construction of gender. Population, 57 (2), 237-267.

Cano Oncala, G., Esteva Antonio, I., e Bergero, T. (2006). Reflexiones psicológicas sobre el proceso transexual mujer a hombre. Em E. Gómez-Gil e I. E. Antonio (Eds.), Ser transexual (pp. 251-267). Glosa. 
Chatton, B. (2001). Picture Books for Preschool Children: Exploring Gender Issues with Three- and FourYear-Olds. Em S. Lehr (Ed.), Beauty, brains and brawn: the construction of gender in children's literature (pp. 57-66). Heinemann.

Evans, J. (2015). Challenging and controversial picturebooks: creative and critical responses to visual texts. Routledge.

Gavilán, J. (2018). Infancia y transexualidad. Ediciones Mágina.

Gill-Peterson, J. (2018). Histories of the Transgender Child. University of Minnesota Press.

Hamilton, M. C., Anderson, D., Broaddus, M., e Young, K. (2006). Gender stereotyping and underrepresentation of female characters in 200 popular children's picture books: A twenty-first century update. Sex Roles, 55 (11-12), 757-765.

Johnston, R. R. (2011). Gender. In M. O. Grenby e K. Reynolds (Eds.), Children's Literature Studies: A Research Handbook (pp. 151-161). Palgrave Macmillan.

Lehr, S. (2001). The Hidden Curriculum: Are We Teaching Young Girls to Wait for the Prince? Em S. Lehr (Ed.), Beauty, brains and brawn: the construction of gender in children's literature (pp. 1-20). Heinemann.

Madalena, E. e Ramos, A. M. (2021). Gender Diversity in Picturebooks: Challenges of a Taboo Topic in Portuguese Schools. Em G. Haaland, B. Kümmerling-Meibauer, e Å. M. Ommundsen (Eds.), Exploring Challenging Picturebooks in Education: International Perspectives on Language and Literature Learning (pp. 143-160). Routledge.

McCabe, J., Fairchild, E., Grauerholz, L., Pescosolido, B. A., e Tope, D. (2011). Gender in twentieth-century children's books: Patterns of disparity in titles and central characters. Gender and Society, 25 (2), 197226.

Narahara, M. (1998). Gender Bias in Children's Picture Books: A Look at Teachers' Choice of Literature. https ://files.eric.ed.gov/fulltext/ED419247.pdf

Norton, J. (1999). Transchildren and the Discipline of Children's Literature. The Lion and the Unicorn, 23 (3), 415-436.

Nunes, A. F. R. (2017). Era uma vez... Estereótipos de Género nos Livros Infantis. ISCTE-IUL.

Paynter, K. C. (2011). Gender Stereotypes and Representation of Female Characters in Children's Picture Books. Liberty University.

Platero, R. (2014). Trans*exualidades: Acompañamiento, factores de salud y recursos educativos. Bellaterra.

Ramos, A. M., Mourão, S., e Cortez, M. T. (Eds.). (2017). Fractures and disruptions in children's literature. Cambridge Scholars Publishing.

Reynolds, K. (2007). Radical children's literature: future visions and aesthetic transformations in juvenile fiction. Palgrave Macmillan.

Rodrigues, P. (2003). Questões de género na infância. Instituto Piaget.

Scott, K. P. (1986). Effects of Sex-Fair Reading Materials on Pupils' Attitudes, Comprehension, and Interest. American Educational Research Journal, 23 (1), 105-116.

Shavit, Z. (2004). Poética da Literatura para Crianças. Caminho.

Stephens, J. (2018). Picturebooks and Ideology. Em B. Kümmerling-Meibauer (Ed.), The Routledge Companion to Picturebooks (pp. 137-145). Routledge.

Weitzman, L. J., Eifler, D., Hokada, E., e Ross, C. (1972). Sex-Role Socialization in Picture Books for Preschool Children. American Journal of Sociology, 77 (6), 1125-1150. 
Citar: Madalena, Emanuel Verdade da (2021). Deixem as crianças em paz: a censura de livros para crianças com temas LGBTIQ+. Elos. Revista de Literatura Infantil e Xuvenil, 8, "Artigos", 1-15. ISSN-e 2386-7620. DOI http://dx.doi.org/10.15304/elos.8.7969 